\title{
Shaker Table Design for Electronic Device Vibration Test System
}

\author{
Waluyo Adi Siswanto, Mohd Norihan Ibrahim, Mohd Amran Madlan, and Siti Mariah Mohamad
}

\begin{abstract}
A general purpose vibration test system has been developed to provide a testing platform for electronic devices. This paper presents the design of the shaker table for the platform-testing base where an electronic device will be placed and excited by the vibration exciter. Three design models are first analyzed their natural frequencies and the corresponding mode shapes. The model with the lightest weight and the highest first natural frequency is then selected to be manufactured. This selected shaker stable can be used in a frequency range of service up to $2500 \mathrm{~Hz}$ and behaves as a rigid body when it vibrates. The maximum dimension of the electronic device that can be placed in the shaker table is $15 \mathrm{~cm}$ square. This paper also provides the general frequency range limitation when the vibration test is used at constant displacement or constant acceleration test. The suggested frequency ranges satisfy all limitation requirements of the shaker.
\end{abstract}

Index Terms — vibration test, natural frequency, shaker table, shock test, endurance test.

\section{INTRODUCTION}

Electronic devices in automotive industries are usually placed in an environment where vibrations may influence their working performance. The vibrations could damage the structure or deteriorate the functionality of their performance. There are some research works have been done to assess endurance of electronic devices under vibration environment [1], [2], [3]. The works cover the assessment method and the instrumentation to conduct the endurance test. The vibration test, however depends on the test equipments. Using different equipments requires different setup and assessment approach.

Whenever an electronic device is installed in a vibration environment, then there should be a guarantee that it will work under such condition. It is therefore a vibration test prior to the installation will be very important to make sure the electronic device has a level vibration endurance. Users should be aware of this vibration specification.

Manuscript received September 3, 2011, revised October 26, 2011.

This work was supported in part by the Research Center and Innovation Office, Universiti Tun Hussein Onn Malaysia, short grant Vot No.0663 and Vot No.0626.

W. A. Siswanto and M. Norihan Ibrahim are with the Department of Engineering Mechanics, Universiti Tun Hussein Onn Malaysia, 86400 Parit Raja, Batu Pahat, Johor, Malaysia (e-mail: was.uthm@gmail.com; norihan@uthm.edu.my)

M. Amran Madlan is with the Noise and Vibration Laboratory, Universiti Tun Hussein Onn Malaysia, 86400 Parit Raja, Batu Pahat, Johor, Malaysia ( e-mail: amran@uthm.edu.my)

Siti Mariah Mohamad is with the Faculty of Mechanical and Manufacturing Engineering, Universiti Tun Hussein Onn Malaysia, 86400 Parit Raja, Batu Pahat, Johor, Malaysia ( e-mail: ctm_mariah@gmail.com)
There are several types of vibration test systems. In regard to the vibration control and the generating signals, a fuzzy control can be used [4] or as a closed loop system [5]. The vibration direction can be one axis in horizontal, vertical or inclined axis [6], and even multiple directions up to six axes [7], [8].

For a specific vibration test system for electronic computer devices with the dimensions not more than $15 \mathrm{~cm} \mathrm{x} 15 \mathrm{~cm}$ square, a vibration testing system in Vibration Laboratory Universiti Tun Hussein Onn Malaysia (UTHM) has been designed [9]. The installation arrangement is depicted in Fig. 1. The direction of the vibration is unidirectional vertical axis.

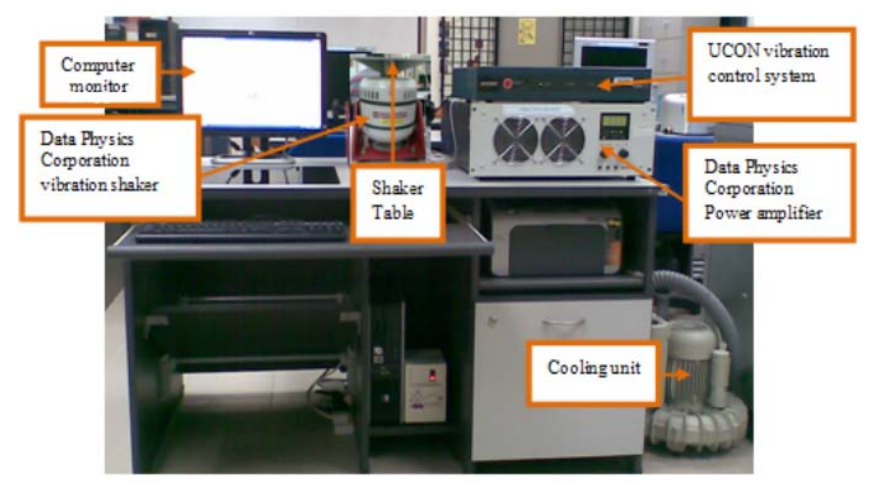

Fig. 1. Vibration test system for electronic device.

The system as shown in Fig. 1 consists of an UCON integrated controller and 4-channel data acquisition system [10], a set of Data Physics exciter system (vibration shaker and power amplifier with cooling unit) and a shaker table [11]. The integrated controller sends vibration signal definition and at the same time picks up vibration output from the shaker table and the test point at the electronic device. The signal obtained from the shaker table can be used as a feedback input for the signal correction in a closed loop control system, or as a controlled signal to see the accuracy of the generated input. The schematic setup diagram of the vibration test system is illustrated in Fig. 2.

The vibration testing system is designed based on the diagram illustrated in Fig. 2. The vibration of the shaker is defined in the vibration controller. The vibration from the shaker is then transmitted to the shaker table, which is attached on the diaphragm mounting located on the top of the shaker. Although the shaker table is designed to be rigid and transmit the vibration from the shaker, a feedback control should be used and send back to the controller for the automatic signal adjustment. For this purpose, an accelerometer is attached on the surface of the shaker table and sends the signal back to the controller. This is a close 
loop system where the vibration on the table's surface is exactly the same with that has been defined by the vibration controller. When open loop is intended, this feedback system is not activated.

The response of the testing object (electronic device) is also recorded. The structural vibration behavior of the device can be examined. At the same time, the working functionality of the device can be monitored if an external functional testing system is attached to the device. The functional performance of the device can be monitored under severe vibration environment.

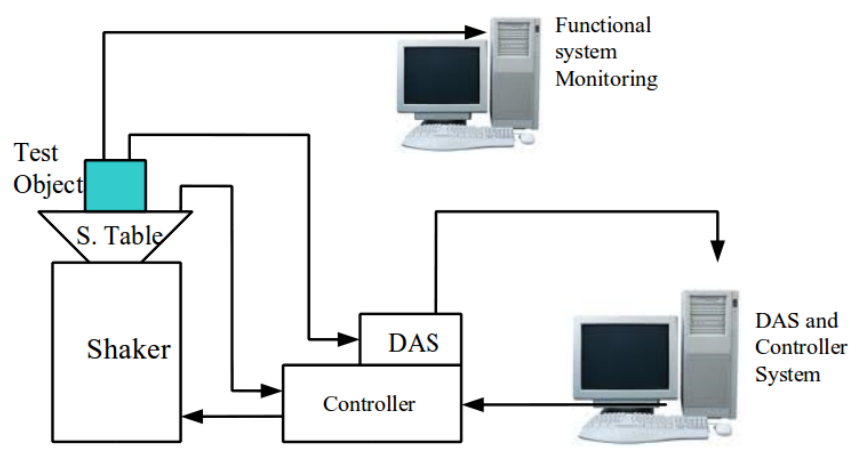

Fig. 2. Vibration test system diagram.

The shaker table is designed to be the test platform where the testing object (electronic device) is attached on the table. The shaker is a light structure made of aluminum. As a surface platform, the table should behave as a rigid body to transmit vibration from the shaker to the testing object.

\section{VibRATION TESTING TyPES}

There are several types of vibration testing can be defined from the controller: Random Test, Sine on Random, Random on Random, Sine and Random on Random, Shock Test, Shock Response Spectrum, Transient Time History Control, Road Simulation, Sine Sweep Test, and Resonance Search Track and Dwell (RSTD) Test [10]. The graphical illustration of the available tests is shown in Fig. 3.

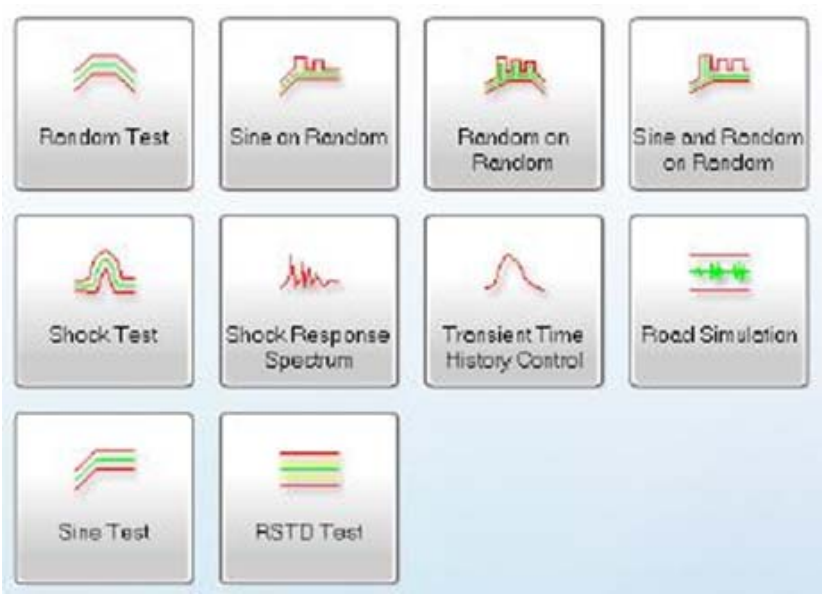

Fig. 3. Types of vibration tests.

\section{ShaKer TABLE Design AND ANALYsis}

The testing object (an electronic device) should be placed on the table surface as illustrated in Fig. 4. During the vibration test, the testing surface of the table should always behave as a flat surface so the table transmits the vibration from the shaker to the object without any structural resonance. This condition should be achieved only if the table is a rigid body which does not deform.

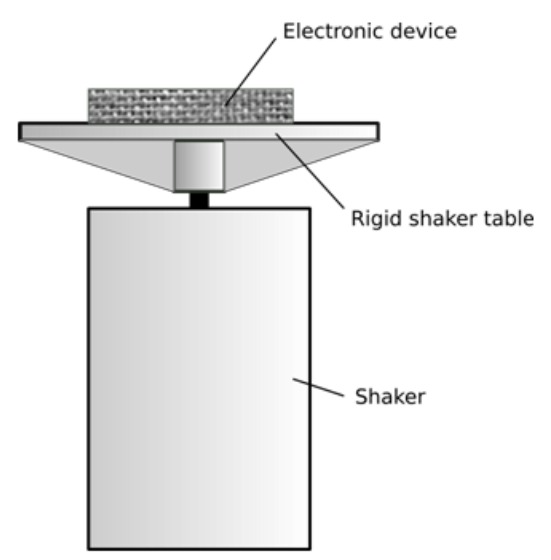

Fig. 4. Shaker table, test object and shaker.

However, since the shaker table is made of Aluminium, this is always flexible and deforms when it vibrates. The structure starts vibrating in a flexible mode at the first natural frequency, which is the first occurrence of the structural resonance. This implies that the table behaves in a rigid mode only in the range of frequency from $0 \mathrm{~Hz}$ to the first natural frequency. Any vibration test should be conducted below the first natural frequency of the shaker table.

Considering the first natural frequency of the table determines the limitation of the frequency range, then the first natural frequency is the main criteria to select the table. The higher first natural frequency will be the better design as it provides a wider frequency range of service. Another consideration is the weight of the table. The lower weight of the table the higher weight of the test object can be placed on the table.

There are three initial designs of the shaker table: Model 1, Model 2 and Model 3. The main dimensions of these design models are identical, i.e. $20 \mathrm{~cm}$ x $20 \mathrm{~cm}$ table surface. The height of the table is $15 \mathrm{~cm}$ with 8 ribs. The structure of the rib is different in each model. The illustration of the three models is shown in Fig. 5. Model 1 has sharp ribs connecting to the bottom main surface, while in Model 2 the ribs are not sharp but squared. As for Model 3, square stiffeners at the bottom of the main surface are added.

From the finite element analysis results [9], the first natural frequency of each model is written in Table I. The first natural frequency of the first model $(0.88 \mathrm{Kg})$ is $2587.5 \mathrm{~Hz}$. The vibration mode is a membrane deformation of the surface. In model 2, the stiffness of the ribs are increased by changing the structure of the edges. It is expected to increase the membrane stiffness of the surface. However, this new rib design increases the mass of the structure resulting the decreased of the first natural frequency, from $2587.5 \mathrm{~Hz}$. to $2384.2 \mathrm{~Hz}$. Similar attempt in model 3, the additional stiffener at the bottom of the surface cannot shift the first natural frequency higher due to the additional mass of the 
structure. It is a bit higher than model 2 but still below the first natural frequency of model 1 .

Considering the comparison results collated in Table I, model 1 has the highest frequency with the lightest mass. Model 1 can provide wider frequency coverage compared to other models. The frequency coverage specification that will be allowed using the shaker table model 1 is in the range of 0 $\mathrm{Hz}$ to $2587.5 \mathrm{~Hz}$. For a safety reason, to make sure that vibration testing frequency is not close to its first resonance, then the frequency $2500 \mathrm{~Hz}$ is set as the highest frequency of the vibration test using this shaker table model 1 .

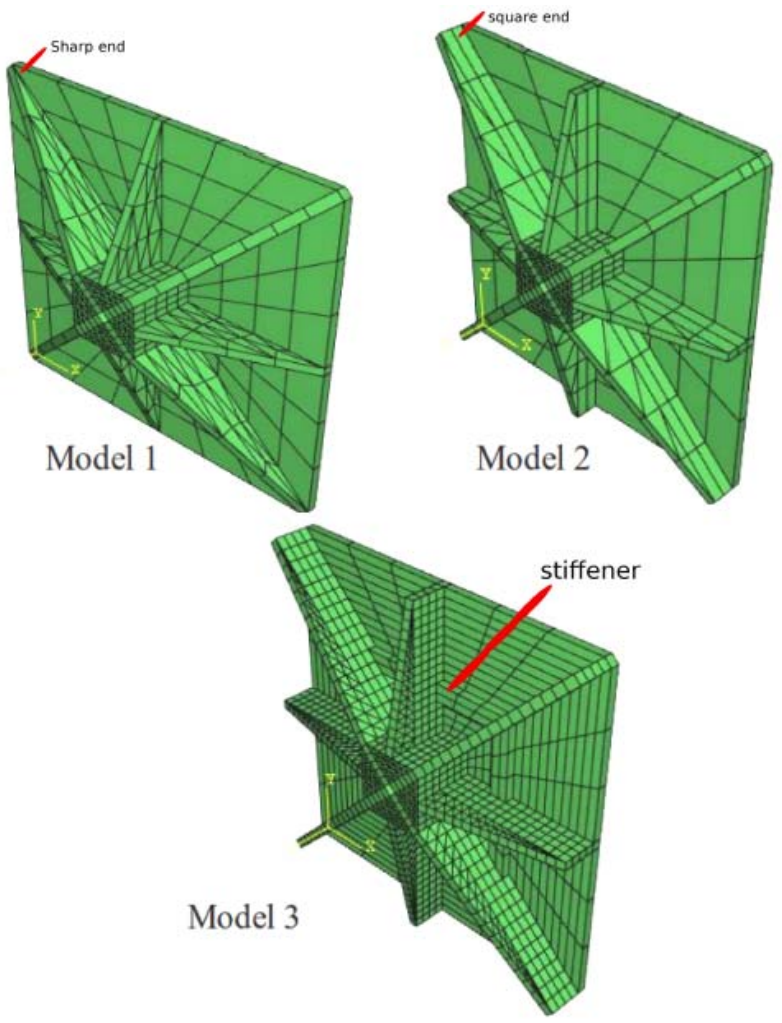

Fig. 5. Three shaker table models.

In model 1 , if the vibration frequency testing is at 2587.5 $\mathrm{Hz}$, the table resonates and the surface will have a circular membrane vibration, as illustrated in Fig. 6. Unsymmetrical bending of the surface occurs at $2633.6 \mathrm{~Hz}$ (Fig. 7), while half bending occurs at $2800.0 \mathrm{~Hz}$ (Fig. 8).

These disturbing vibration deformations to the device object located on the surface will not happen as long as the vibration frequency is below $2500 \mathrm{~Hz}$.

\begin{tabular}{ccc}
\multicolumn{3}{c}{ TABLE I: FIRST NATURAL FREQUENCY } \\
\hline Model & Mass $(\mathrm{kg})$ & Freq $(\mathrm{Hz})$ \\
\hline Model 1 & 0.88 & 2587.5 \\
Model 2 & 0.96 & 2384.2 \\
Model 3 & 1.04 & 2399.6 \\
\hline
\end{tabular}

The finished product of the shaker table manufactured from design model 1 is depicted in Fig. 9. The center block and the surface are welded. All fixed attachments of ribs to the center block and the lower surface are glued with a mixture of epoxy and resin. This cold fixing technique is applied to avoid any material deformation due to high temperature welding that could affect the flatness of the surface.

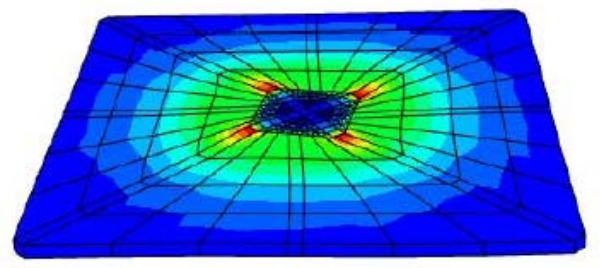

Fig. 6. $1^{\text {st }}$ natural frequency, $2587.5 \mathrm{~Hz}$.

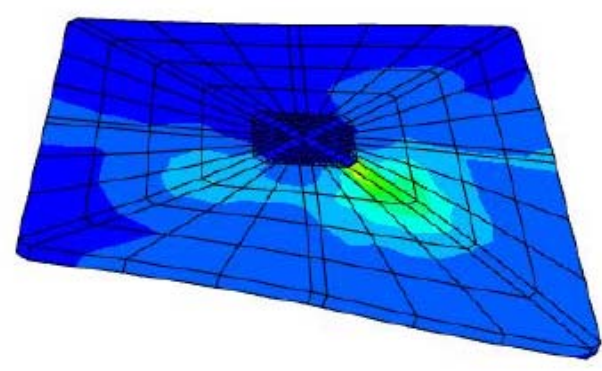

Fig. 7. $2^{\text {nd }}$ natural frequency, $2633.6 \mathrm{~Hz}$.

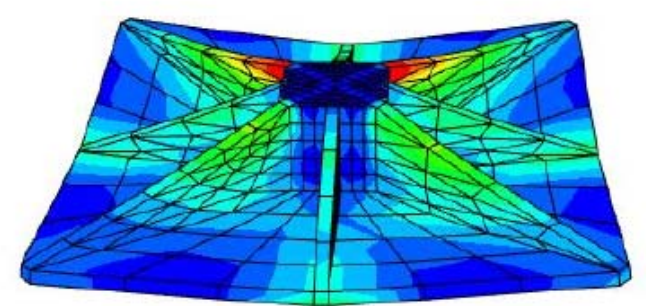

Fig. 8. $5^{\text {th }}$ natural frequency, $2800 \mathrm{~Hz}$.
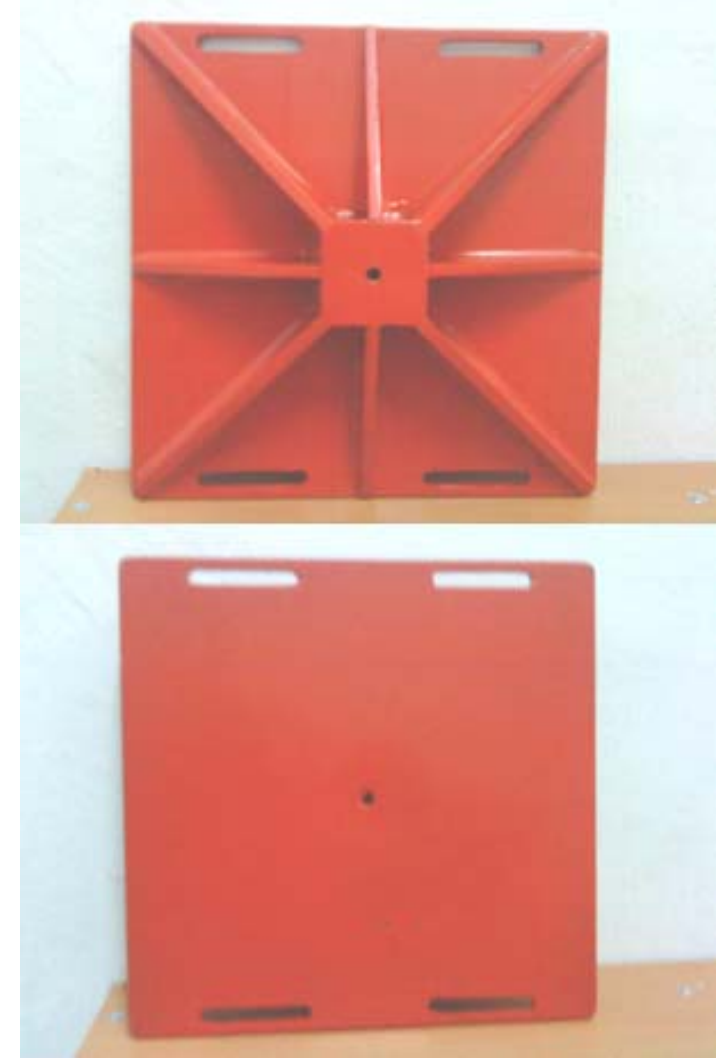

Fig. 9. Manufactured shaker table. 


\section{ViBRATION TESTING LIMITATION}

The testing limitation is mainly caused by the capacity of the vibration exciter (shaker) to provide the maximum acceleration. The installed shaker manufactured by the Data Physics [11] is able to provide acceleration up to maximum $93 \mathrm{~g}\left(\approx 900 \mathrm{~m} / \mathrm{s}^{2}\right)$ with the maximum vertical load of $3 \mathrm{~kg}$. The maximum velocity allowed is $1.5 \mathrm{~m} / \mathrm{s}$. The membrane of the shaker should not displace more than $5 \mathrm{~mm}$.

Since the shaker table is $0.88 \mathrm{~kg}$, the maximum of testing object is limited $2.12 \mathrm{~kg}$ and the attachment size is not more than $20 \mathrm{~cm}$. For a safety reason, only $1.5 \mathrm{~kg}$ is allowed to be mounted on the shaker table. As for the attachment size, only an electronic device with maximum width of $15 \mathrm{~cm}$ allowed due to the space required for the clamping system.

To determine the general specification of the service coverage, a vibration relationships of acceleration stated in Eq. 1 is used.

$$
a=4 \pi^{2} f^{2} x
$$

If a vibration test is performed at a constant displacement $x$, the maximum vibration frequency that will not exceed the maximum acceleration capacity of the shaker $\left(\approx 900 \mathrm{~m} / \mathrm{s}^{2}\right)$ can be calculated by:

$$
f=\sqrt{\frac{900}{4 \pi^{2} \times 10^{-3}}}
$$

where the frequency $f$ is expressed in $\mathrm{Hz}$ and the displacement $x$ is in mm.

The calculated maximum frequencies on various displacements are collated in Table II. It can be seen that the maximum frequency decreases as the displacement increases. In vibration test with high displacement amplitudes, the maximum frequencies cannot be used since the shaker will reach the allowable velocity values $(1.5 \mathrm{~m} / \mathrm{s})$.

In terms of velocity, the general expression of velocity can be written as:

$$
v=2 \pi f x
$$

or

$$
f=\frac{v}{2 \pi x}
$$

TABLE II: CALCULATED MAXIMUM FREQUENCY AT MAXIMUM

\begin{tabular}{cccc}
\multicolumn{4}{c}{ ACCELERATION $900 \mathrm{M} / \mathrm{s}^{2}$} \\
\hline Disp $(\mathrm{mm})$ & Max freq $(\mathrm{Hz})$ & Velo $(\mathrm{m} / \mathrm{s})$ & Accel $\left(\mathrm{m} / \mathrm{s}^{2}\right)$ \\
\hline 0.002 & 3376 & 0.04 & 900 \\
0.004 & 2387 & 0.06 & 900 \\
0.05 & 675 & 0.21 & 900 \\
0.1 & 477 & 0.30 & 900 \\
1 & 151 & 0.95 & 900 \\
2 & 107 & 1.34 & 900 \\
3 & 87 & $1.64(>1.5)$ & 900 \\
4 & 75 & $1.90(>1.5)$ & 900 \\
5 & 68 & $2.12(>1.5)$ & 900 \\
\hline
\end{tabular}

Considering Eq. 4, the maximum frequencies that will not exceed the allowable velocity of the shaker are shown in Table III.

TABLE III: CALCULATED MAXIMUM FREQUENCY AT MAXIMUM VELOCITY

\begin{tabular}{cccc}
\multicolumn{4}{c}{$1.5 \mathrm{M} / \mathrm{s}$} \\
\hline Disp $(\mathrm{mm})$ & Max freq $(\mathrm{Hz})$ & Velocity $(\mathrm{m} / \mathrm{s})$ & Acceleration $\left(\mathrm{m} / \mathrm{s}^{2}\right)$ \\
\hline 0.05 & 4775 & 1.5 & $45000(>900)$ \\
0.1 & 2387 & 1.5 & $22500(>900)$ \\
1 & 239 & 1.5 & $2250(>900)$ \\
2 & 119 & 1.5 & $1125(>900)$ \\
3 & 80 & 1.5 & 750 \\
4 & 60 & 1.5 & 562 \\
5 & 48 & 1.5 & 450 \\
\hline
\end{tabular}

Since the vibration test should not exceed the maximum allowable velocity and acceleration, Table II and Table III should be all considered. Graphically, the allowable vibration test coverage in constant displacement is illustrated in Fig. 10 .

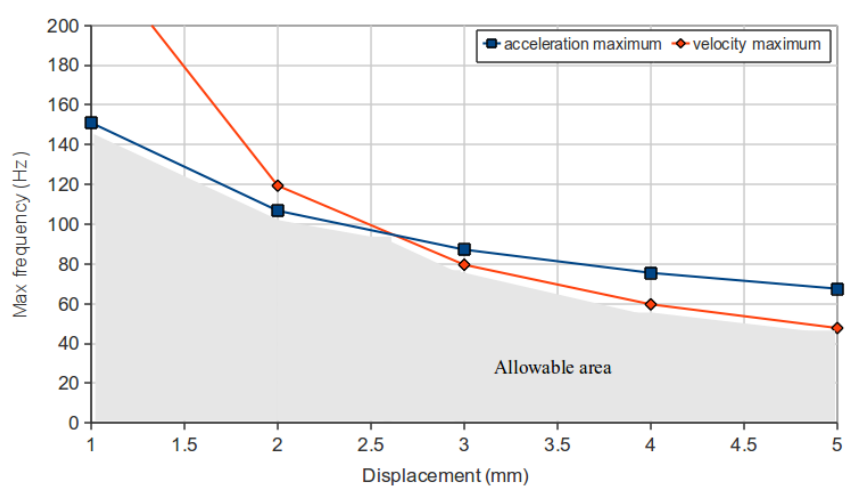

Fig. 10. Allowable testing area.

After considering the shaker's requirements both the maximum acceleration and the maximum velocity, the frequency range summary for constant displacement vibration test can be found in Table IV. As an illustration, if a vibration test with constant displacement amplitude of $4 \mathrm{~mm}$ will be performed, the vibration frequency should not be higher than $60 \mathrm{~Hz}$.

\begin{tabular}{cc} 
TABLE IV: FREQUENCY RANGE FOR CONSTANT DISPLACEMENT TEST \\
\cline { 1 - 2 } Disp (mm) & Frequency Range $(\mathrm{Hz})$ \\
\hline 0.004 & $0-2387$ \\
0.05 & $0-675$ \\
0.1 & $0-477$ \\
1 & $0-151$ \\
2 & $0-107$ \\
3 & $0-80$ \\
4 & $0-60$ \\
5 & $0-48$ \\
\hline
\end{tabular}

Another possibility in vibration test considers the acceleration instead of displacement. The vibration level is not defined by the displacement vibration amplitude but 
acceleration amplitude. The requirement that the shaker should not reach $1.5 \mathrm{~m} / \mathrm{s}$ must be taken into consideration.

Combining Eq. 1 and Eq. 3, the velocity of the shaker can be calculated by:

$$
v=2 \pi f \frac{a}{4 \pi^{2} f^{2}}
$$

Since the maximum allowable velocity is $1.5 \mathrm{~m} / \mathrm{s}$, the minimum frequency at acceleration level $a$ can be determined by:

$$
f=\frac{a}{3 \pi}
$$

An illustration of displacement and velocity vibration amplitudes at vibration acceleration $900 \mathrm{~m} / \mathrm{s}^{2}$ is shown in Fig. 11. The velocity chart shows that below $95.5 \mathrm{~Hz}$ the velocity amplitude will go beyond $1.5 \mathrm{~m} / \mathrm{s}$. This information says that when vibration test is conducted in acceleration level of 900 $\mathrm{m} / \mathrm{s}^{2}$, the vibration test must not be performed below $95.5 \mathrm{~Hz}$. The illustration shown in Fig. 11 also shows that at low frequency the displacement could be very high. The vibrating membrane of the shaker will be broken if the displacement is too high. It is therefore the displacement is limited to $5 \mathrm{~mm}$ only.

The minimum frequency calculations must consider Eq. 6 and Eq. 2. The selected minimum frequency is the highest result calculated by Eq. 6 and Eq. 2, to satisfy that displacement should be less than $5 \mathrm{~mm}$ and the velocity falls below $1.5 \mathrm{~m} / \mathrm{s}$.

It should also be noted that the vibration test should not be conducted above $2500 \mathrm{~Hz}$ since the shaker table cannot be used above $2500 \mathrm{~Hz}$. Therefore, performing vibration test at acceleration amplitude level of $900 \mathrm{~Hz}$ the frequency range must be in between $95.5 \mathrm{~Hz}$ and $2500 \mathrm{~Hz}$.

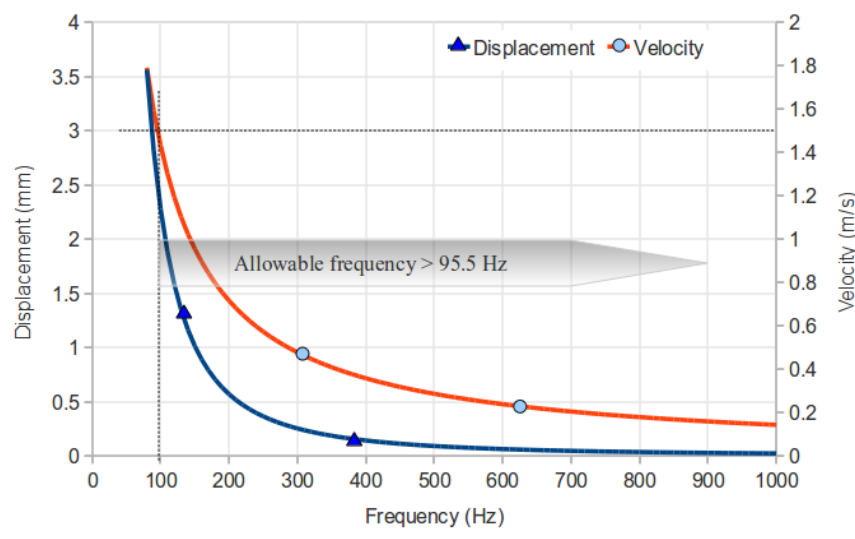

Fig. 11. Allowable frequency range at max acceleration $900 \mathrm{~m} / \mathrm{s}^{2}$.

The compiled calculation frequency range for various

\begin{tabular}{|c|c|c|c|}
\hline $\operatorname{Accel}\left(\mathrm{m} / \mathrm{s}^{2}\right)$ & min freq (Eq.6) & $\min$ freq (Eq.6) & Freq range $(\mathrm{Hz})$ \\
\hline 900 & 95.5 & 67.5 & $95.5-2500$ \\
\hline 800 & 84.9 & 63.7 & $84.9-2500$ \\
\hline 700 & 74.3 & 59.6 & $74.3-2500$ \\
\hline 600 & 63.7 & 55.1 & $63.7-2500$ \\
\hline 500 & 53.1 & 50.3 & $63.1-2500$ \\
\hline 400 & 42.4 & 45.0 & $45.4-2500$ \\
\hline 300 & 31.8 & 39.0 & $39.0-2500$ \\
\hline 200 & 21.2 & 31.8 & $31.8-2500$ \\
\hline 100 & 10.6 & 22.5 & $22.5-2500$ \\
\hline 90 & 9.5 & 21.4 & $21.4-2500$ \\
\hline 80 & 8.5 & 20.1 & $20.1-2500$ \\
\hline 70 & 7.4 & 18.8 & $18.8-2500$ \\
\hline 60 & 6.4 & 17.4 & $17.4-2500$ \\
\hline 50 & 5.3 & 15.9 & $15.9-2500$ \\
\hline 40 & 4.2 & 14.2 & $14.2-2500$ \\
\hline 30 & 3.2 & 12.3 & $12.3-2500$ \\
\hline 20 & 2.1 & 10.1 & $10.1-2500$ \\
\hline 10 & 1.1 & 7.1 & $7.1-2500$ \\
\hline 9 & 1.0 & 6.8 & $6.8-2500$ \\
\hline 8 & 0.8 & 6.4 & $6.4-2500$ \\
\hline 7 & 0.7 & 6.0 & $6.0-2500$ \\
\hline 6 & 0.6 & 5.5 & $5.5-2500$ \\
\hline 5 & 0.5 & 5.0 & $5.0-2500$ \\
\hline 4 & 0.4 & 4.5 & $4.5-2500$ \\
\hline 3 & 0.3 & 3.9 & $3.9-2500$ \\
\hline 2 & 0.2 & 3.2 & $3.2-2500$ \\
\hline 1 & 0.1 & 2.3 & $2.3-2500$ \\
\hline
\end{tabular}
acceleration levels are documented in Table V.

\section{CONCLUSIONS}

A Shaker table has been designed and manufactured to suit with the shaker. This shaker table can be a rigid moving platform in a frequency range up to $2500 \mathrm{~Hz}$. When it used beyond $2500 \mathrm{~Hz}$, the table could be in a resonance condition so that the surface will vibrate not in a flat movement.

In general many types of testing can be conducted by the vibration test system; Random Test, Sine on Random, Random on Random, Sine and Random on Random, Shock Test, Shock Response Spectrum, Transient Time History Control, Road Simulation, Sine Sweep Test, and Resonance Search Track and Dwell (RSTD). The controller defines this testing mode.

As for the sine sweep testing (constant displacement or constant acceleration), the frequency range of service will not be in the general range from $0 \mathrm{~Hz}$ to $2500 \mathrm{~Hz}$, but depending on the constant setting value of the vibration amplitude level. This is due to the limitation of the shaker that the vibration acceleration and velocity are not exceeding $93 \mathrm{~g}$ and $1.5 \mathrm{~m} / \mathrm{s}$, respectively. The vibrating membrane of shaker should also not displace more than $5 \mathrm{~mm}$.

The frequency range of in constant displacement vibration test is concluded in Table IV whereas in constant acceleration test, the service range follows the range written in Table V. 


\section{ACKNOWLEDGMENT}

The authors would like to thank Dr. Shahruddin Mahzan for his support and En. Mohd Zainorin Kasron, the technician at Noise and Vibration Laboratory, UTHM, for setting up the equipments.

\section{REFERENCES}

[1] J. Wu, R. R. Zhang, Q. Wu, and K. K. Stevens, "Environmental vibration assessment and its applications in accelerated tests for medical devices," Journal of Sound and Vibration, vol. 267, no. 2, pp. $371-383,2003$.

[2] F. Yap, N. Vahdati, and H. Harmoko, "Design and analysis of vibration isolation systems for hard disk drives," Journal of Magnetism and Magnetic Materials, vol. 303, no. 2, pp. e52 -e56, 2006, the 6th International Symposium on Physics of Magnetic Materials.

[3] C. Mechefske and Q. Sun, "Failure detection in automotive light assemblies during vibration endurance testing," The International Journal of Advanced Manufacturing Technology, vol. 51, pp. 799-810, 2010.

[4] K. Rana, "Fuzzy control of an electrodynamic shaker for automotive and aerospace vibration testing," Expert Systems with Applications, vol. 38, no. 9, pp. $11335-11346,2011$.

[5] H. Gomes, D. dos Santos Gaspareto, F. de Souza Ferreira, and C. Thomas, "A simple closed-loop active control of electrodynamic shakers by acceleration power spectral density for environmental vibration tests," Experimental Mechanics, vol. 48, pp. 683-692, 2008.

[6] A. G. Piersol, "The development of vibration test specifications for flight vehicle components," Journal of Sound and Vibration, vol. 4, no. 1, pp. $88-115,1966$.

[7] F. D. Connick, W. Desmet, and P. Sas, "Installation and performance testing of a high frequency 6-dof shaker table," Department of Mechanical Engineering, Katholieke Universiteit Leuven, Tech. Rep., 2009.

[8] F. D. Coninck, W. Desmet, P. Sas, and D. Vaes, "Multisine shock and vibration testing using a high-frequency 6-dof shaker table," in Tenth International Congress on Sound and Vibration, The International Institute of Acoustics and Vibration. Stockholm, Sweden: The International Institute of Acoustics and Vibration, July 2010, pp. 1-8.
[9] W. A. Siswanto, M. N. Ibrahim, M. A. Madlan, and S. M. Mohamad, "General purpose vibration test system for electronic devices," in Proceedings of Malaysian Technical Universities Conference on Engineering and Technology (MUCEET2010), Malaysian Technical University Network (MTUN). Pahang: MTUN, 28-29 June 2010, pp. 305-310.

[10] UCON Vibration Control System User Manual, Revision 4.0 ed., Hangzhou Econ Technologies Co. Ltd.

[11] Shaker Data Specification, Data Physics, 2009.

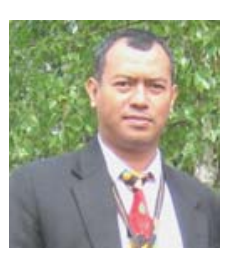

Waluyo Adi Siswanto is a senior lecturer at the Dept Engineering Mechanics,Universiti Tun Hussein Onn Malaysia (UTHM). He received his bachelor degree in mechanical engineering from Gadjah Mada University, Indonesia, and completed his M.Eng and $\mathrm{PhD}$ from RMIT, Australia. He is one of the contributors in an open source Finite Element Program Suite, Impact (http://impact.sourceforge.net/).

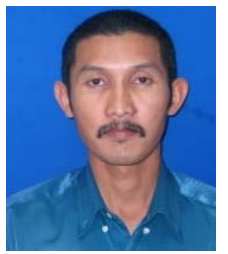

Mohd Norihan Ibrahim is a lecturer at Department Engineering Mechanics, Universiti Tun Hussein Onn Malaysia (UTHM). He received his bachelor degree in mechanical engineering from the University of Plymouth, UK, and completed his M.Eng (Mechanical) from Universiti Tun Hussein OnnMalaysia (UTHM).

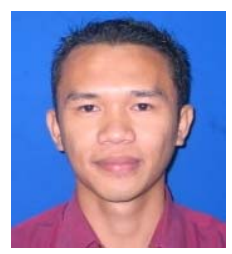

Mohd Amran Madlan is a lecturer at Department Engineering Mechanics, Universiti Tun Hussein Onn Malaysia (UTHM). He received his bachelor degree in mechanical engineering from Universiti Tun Hussein Onn Malaysia (UTHM), and he is currently studying his Master by course in UTHM.

Siti Mariah Mohamad is now working as a field engineer in a private company in Malaysia. She received her bachelor degree in mechanical engineering from Universiti Tun Hussein Onn Malaysia (UTHM). 